\title{
Commentary on papers in Advances in Psychiatric Treatment
}

It is the intention of the Editorial Board to establish dialogue, discussion, debate and even dispute among our readership and we aim to publish correspondence, however derogatory! With this issue we are adding another contribution to the possibility of debate by having an item called 'Commentary' for some of the papers. The commentator will usually come from a different discipline or subspeciality from the original author and will therefore give the matter under discussion a different slant. We hope our commentators will be controversial or will at least produce some new ideas and perspectives. This will give another side to the arguments and discussions of treatment and will also expand particular areas. It is the nature of the article itself which will dictate the content of the commentary. We hope that this will make the journal both more lively and informative.

\section{Comment from Richard Lingham}

Professor Gournay's commentary on the issues and roles in mental health nursing could equally have been titled: situation and process, skills and experience, genericism and specialism, clinical and eclectic, or proactive and preventive. His research review supports a viewpoint at the structured/ tested end of this continuum, where he sees ready evidence that nurses now require clinically focused training and re-training if they are to provide care and treatment for patients with the most seriously disabling mental illnesses. This reinforces the Butterworth Report's conclusions, the Health of the Nation's expectations and the specifications in Building Bridges.

Last year, the Clinical Standards Advisory Group on Schizophrenia (DoH, 1995) found "little systematic assessment of mental health nurses' training needs in psychological/family interventions, case management approaches (including assertive outreach), and the assessment of the sideeffects of medication". Also, "in some districts CPNs were unhappy about the stigmatising effects of 'labelling' and did not wish to use the term 'schizophrenia'. This led, on occasion, to a lack of co-ordination between the professions and deployment of their time away from the care of the severely mentally ill."

Professor Gournay recalls research findings from 1990 that only a small minority of patients with schizophrenia see CPNs. His own recent research concludes that their main work with primary health care patients who suffer from depression and anxiety states, is "ineffective and very expensive". He identifies the need to improve standards of management to develop focused methods of work with patients and families, and to instil basic clinical knowledge and awareness.

Much of the nursing story mirrors the path trodden by social workers. In 1970, before all social work and training became generic, six universities provided postgraduate training in psychiatric social work. None does now, but specialism has re-emerged by statutory accident since 1983 , in the form of in-service training for approved social workers, which has expanded from four weeks to six months. In 1995, specialism took more substantial form in the Statement of Competencies for Forensic Social Work published by the Central Council for Education and Training in Social Work.

Many CPNs and social workers will need retraining and reorientation to work competently within the sort of structured programmes operating in Wisconsin, Sydney, and increasingly in this country. Successful assertive outreach work will demand that professional opinions, contributions to clinical judgement and decision making are based on secure knowledge, sound professional philosophies and shared awareness. Patients and carers must feel secure about treatment and care plans. Within their individual capacities, all members of the resultant team should know that the principal sources of understanding of mental illness stem from clinical psychiatry and psychology. The training and practice of those who earn their living in mental health care must acknowledge this reality. Apart from anything else, how can detractors of 'the medical model', when circumstances justify firm opposition to a doctor's views, hope to present a credible opinion if they do not know what they are talking about? 